\title{
فاعلية التدريبات الباليستية على تطوير القدرات البدنية والمستوي الرقمي لناشئي 100 متر
}

$$
\text { عدو }
$$

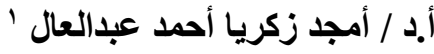

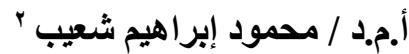 \\ بسنت أبو العلا عبد العظيمّم
}

' أستاذ التدريب الرياضي ورئيس قسم التدريب الرياضي وعلوم الحركة بكلية التربية الرياضية للبنين بجامعة الزقازيق r أستاذ مساعد وقائم بأعمال رئيس قسم نظريات وتطبيقات مسابقات الميدان والمضمار بجامعة قناة السويس " باحثة ماجستير تخصص تدريب رياضي وعلوم الحركة، كلية التربية الرياضية، جامعة قناة السويس3

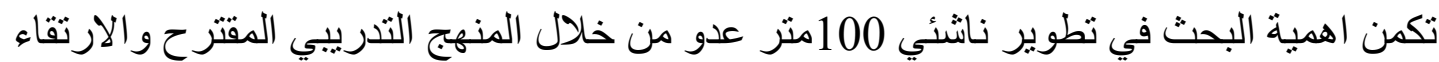
بمستوي الأداء إذ أن التدريب الباليستي اصبح من اكثر الاساليب استخداما في تنمية القدرة العضلية في العديد من الانشطة الرياضية والتي تتطلب دمج اقصى قوة مع اقصى سرعة للعضلة حيث ترتبط بالعلاقة بين القوة و السرعة. حيث استخدم الباحثون اسلوب التدريب الباليستي بالاستيك المطاط على قوة عضلات الطرف السفلى

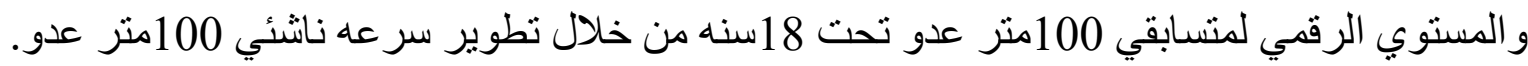

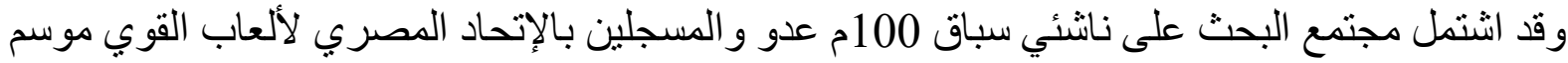

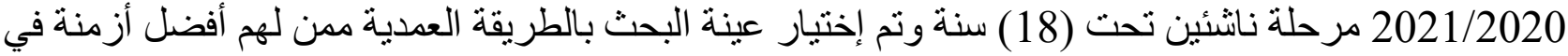
سباق 100م عدو و عددهم (22) لاعب وقد قامت الباحثة بتقسيمهم إلي (6) متسابقين كعينة استطلاعية و (16)

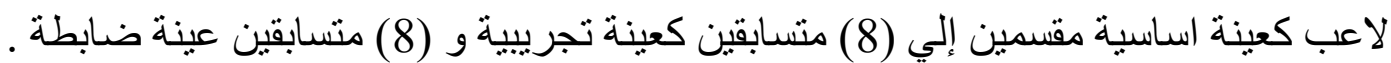

ومن هنا توصل الباحثون في ضوء هدف البحث وفروضله وفى حدود عينة البحث و الإجر اءات التي اتبعها

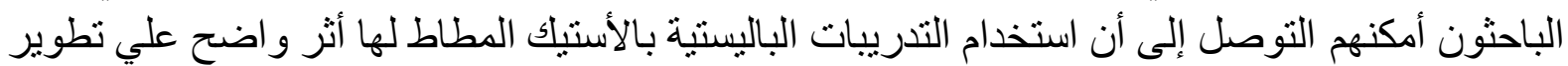

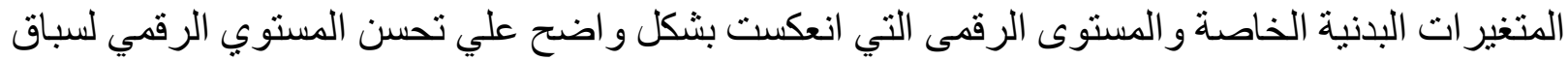

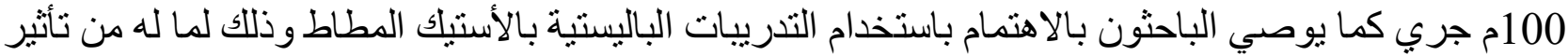
و اضح علي النو احي البدنية التي تنعكس علي تنمية المستوي الرقمي لسباق 100م جري و استخدام التدريبات الباليستية بالأستيك المطاط لتنمية القدر ات البدنية (العامة و الخاصة) فى مختلف الالعاب الجماعية لتئية والفردية.

$$
\text { الكلمات المفتاحية: أساليب التدريب ، السرعة ، التدريب الباليستي ، الأستيك المطاط }
$$


ويتسم العصر الحالي بتطور مذهل في كافة مجالات المعرفة والبحث العلمي و التكنولوجي وما نشاهده اليوم

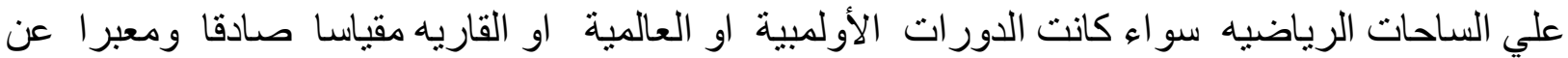

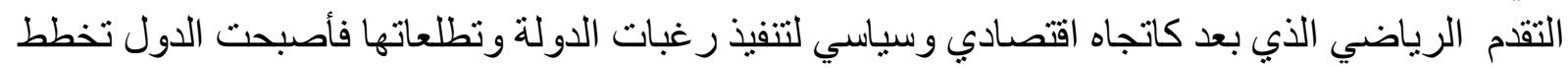
للبطو لات الرياضية المختلفة من خلال متخصصين علي العلم و المعرفة و الأخذ بمبدأ البحث العلمي و المبداني.

حيث يري "بسطويسي احمد" (505) (2005) أن التدريب الرياضي يهدف إلى الوصول بالفرد إلى أعلى يلى المستو يات الرياضية في النشاط الممارس وتختلف الأنشطة الرياضية باختلاف متطلباتها في التدريب و المنافسة

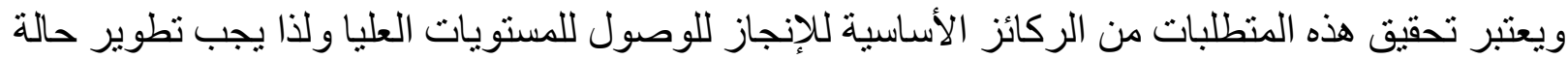

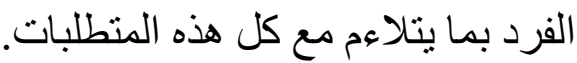

$(69: 10)$

حيث يثير "إياد عبدالله" (2012م) على ان علم التدريب الرياضي يتناول العديد من الوسائل التدريية التي من الممكن تطبيقها بشكل ميداني في مجال التعلم و التدريب مباشرة وأن كل نوع من الفعاليات الرياضية

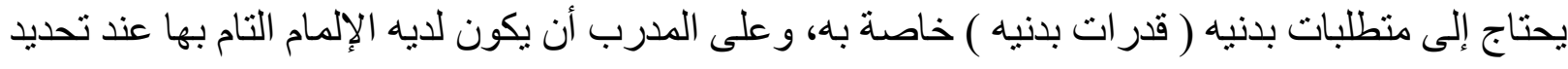

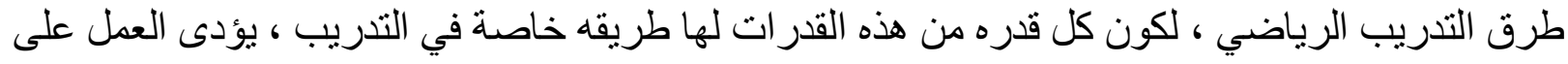

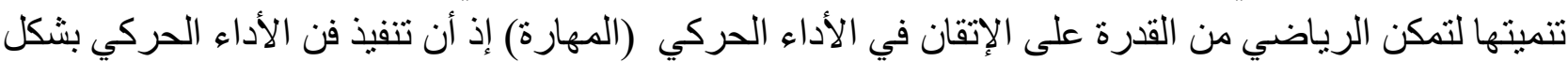

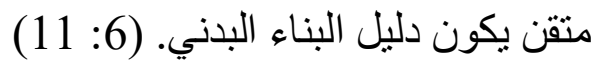

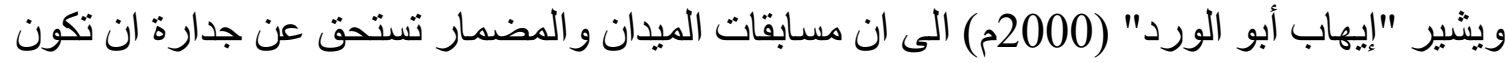
هي أم الرياضات و عروس الدور ات الأولمبية ورياضة أساسية ضمن محتوي المناهج المدرس لمختلف المر احل هل التعليمية، وشعار ها دائما هو (الأقوى - الأسر عـ الأس الأعلى). (102:7)

ويشير "محمد عثمان" (1994 م) إلي ان البر امج التدريبية قد اتخذت شكلا و هيكلا تتظيما يتفق مع التئ

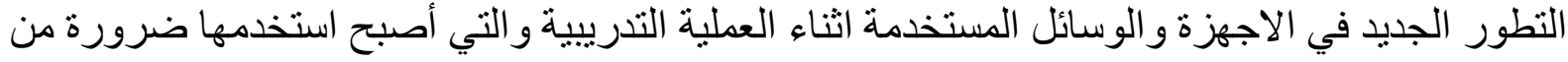
الضروريات التأهيل البدني و المهاري و النفسي لمتسابقين فقد أثثبت بالتجربة ان استخدمها يؤدي إلي ارتفاع التهاع المستويات الرياضية. (34: 153 )

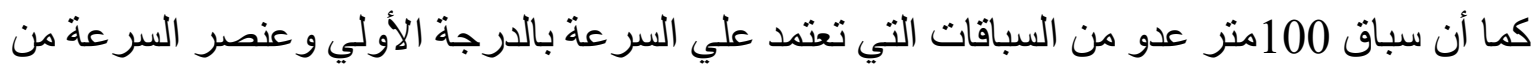

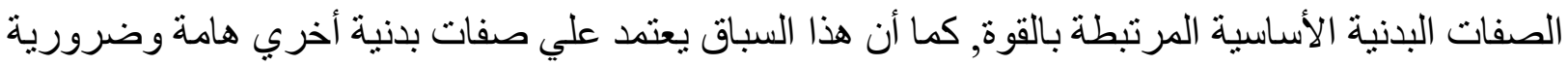

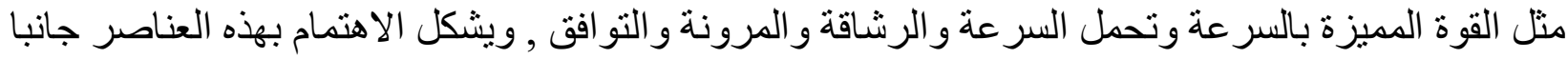

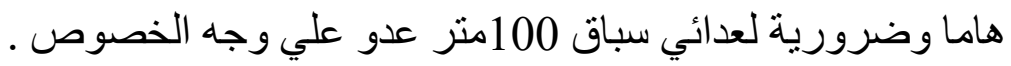

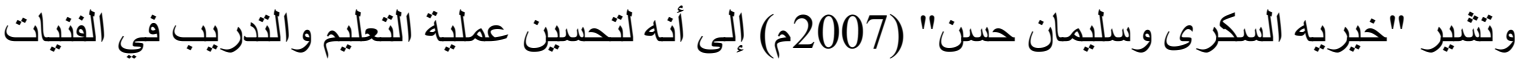

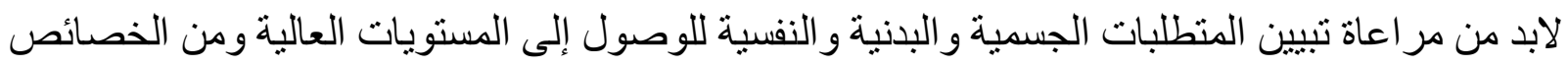


البدنية: القوه القصوى ـ المرونة ـ القوه المميزة بالسر عة ـ السرعة ـ الرشاقة ـ تحمل الاداء ـ التوازن التو افق. (14) (116) ويذكر "عويس الجبالي" (1998م) أنه إذا نظرنا إلي سباق 100متر عدو فنجد أنه أقصر مسابقة في مسابقات المضمار و اسر عها علي الأطلاق و أكثر ها إثارة وقوة ومتعة, ولقد تطور الرقم العالمي ـ (30: 76 ) ولقد تطور الرقم القياسي العالمي لهذه المسابقة بشكل مذهل وسريع ولقد تربع على عرشها أشا العداء

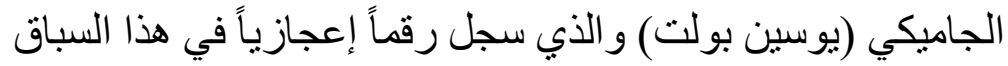

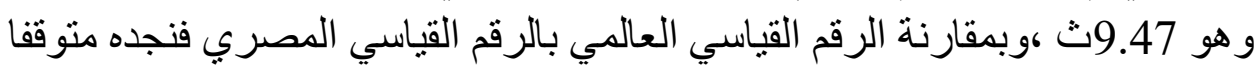

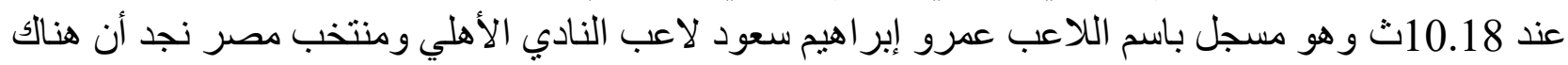
فارقاً كبير ا بين الرقمين , و الذى قد يرجع إلى عو امل كثيرة قد تكون منها الإعداد البدنى الخاص و الذي الذى يتمثنل في

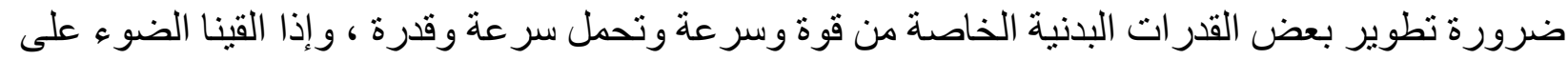
المتطلبات البدنية الخاصة

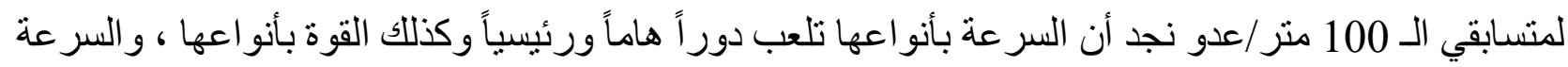
مرتبطة بالقوة وكذلك التو افق العضلي العصبي. وقد ابتكر العلماء طريقة للتدريب تخدم الألعاب التي تتميز

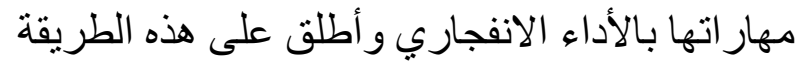

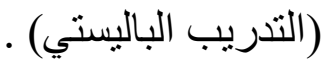
مما سبق يتضح ان العاب القوي تتطلب صفات بدنية ومهارية خاصة تناسب كل مسابقاتها على حدة و100متر عدو احدى مسابقات العاب القوي التي تتميز بمنطلبات بدنية خاصة.

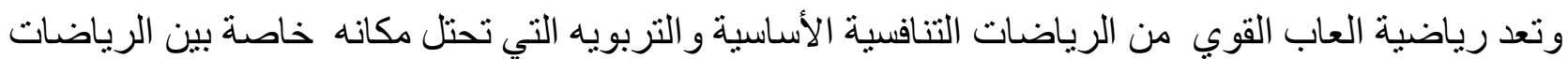

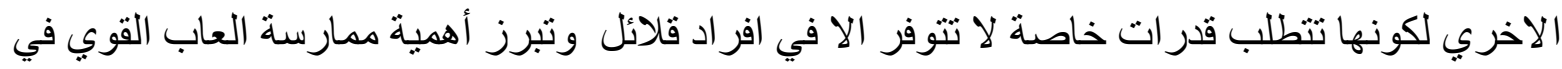

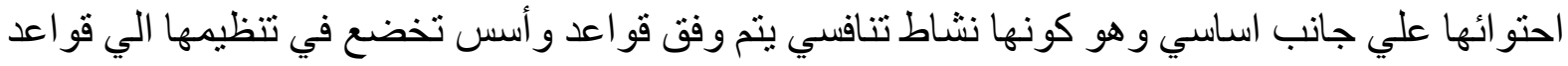
تتعامل مع الجنس البشري علي أسس تربويه تبرز أهمية النشاط التنافسي كنشاط تربوي هادف. ويوضح "زكي درويش" (1997م) أن سر عه العدو 100متر تعتمد علي عاملين أساسين هما طول

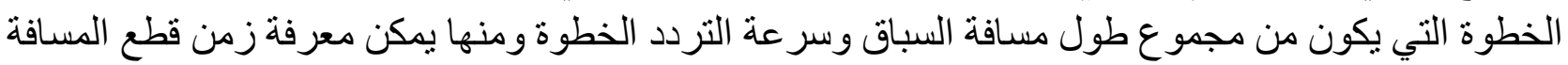

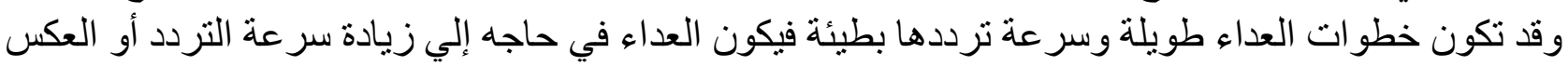

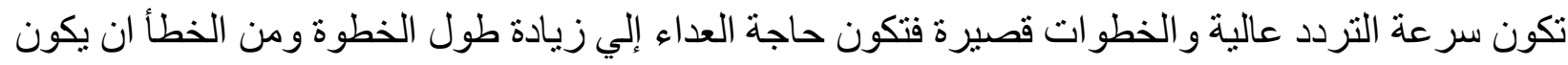
طول الخطوة علي حساب ترددها او يكون سرعة التردد علي حساب طول الخطوة بل يجب ان تكون العلاقة

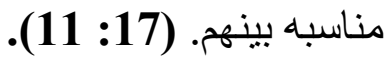


ومن اجل الوصول الي اعلي المستويات 100مثر عدو كان و لابد من التركيز علي قدرات بدنية بعينها

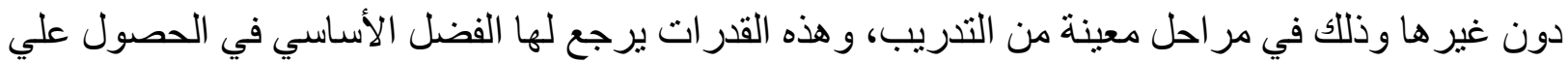

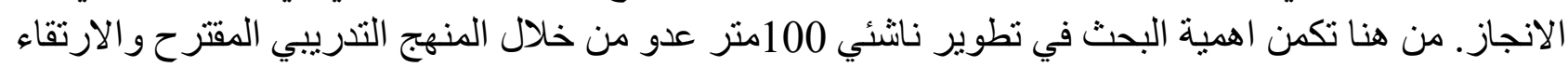
بمستوي الأداء إذ أن التدريب البالستي اصنبح من اكثر الاساليب استخداما في تنمية القدرة العضلية في العديد من الانشطة الرياضية والتي تتطلب دمج اقصى قوة مع اقصى سرعة للعضلة حيث ترتبط بالعلاقة بين القوة

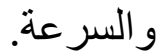

ومن خلال خبرة الباحثة كلاعبة في هذا المجال فقدت لاحظت أن بعض المدربين يعتمدون على تدريب القدر ات البدنية بشكل عام ليس بدقه أداء المهارة بشكل كافي أي لابد أن يكون تدريبهم باتجاه الأداء الحركي

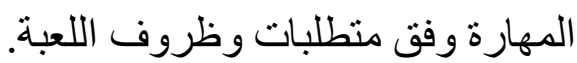
حيث ترى الباحثة أن ضعف المستوى الرقمي لناشئي . . . مثر /عدو وضعف عضلات طرف السفلي خاصهه. نقطنين بجب التنبيه عليهم وعليه توجهت الباحثة إلى در اسة هذه المشكلة من خلال منهج تدريبي مقترح لتطوير المستوى الرقمي

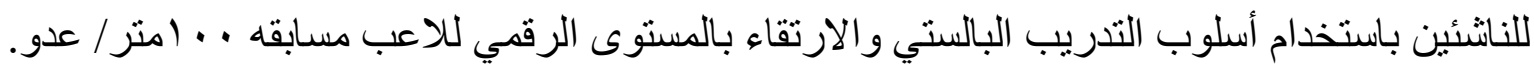

\section{أهداف البحث:}

يهدف هذا البحث إلى التعرف علي تأثير إستخدام اسلوب التدريب الباليستي بالاستيك المطاط على قوة عضلات الطرف السفلى والمستوي الرقمي لمنسابقي 100منر عدو تحت 18سنه من خلال تطوير سر عه ناشئي 100متر عدو.

\section{فرضيات البحث:}

1- توجد فروق داله إحصائياً في المجموعة الضابطة بين القياسيين القبلي والبعدي في المتغيرات البدنية

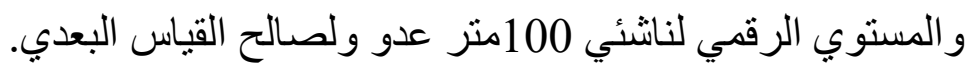

2- توجد فروق داله إحصائياً في المجموعة التجريبية بين القياسيين القبلي و البعدي في المتغير ات البدينية

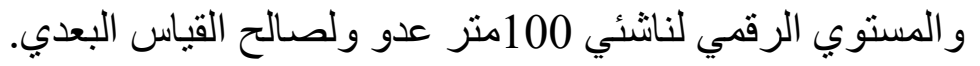
3- يوجد فروق داله إحصائياً بين المجموعتين الضابطة والتجريبية في القياس البعدي في المتغيرات البدنية

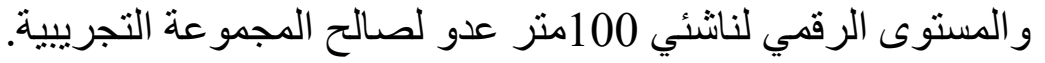


إستخدم الباحثون المنهج التجريبي بإستخدام القياس القبلي و القياس البعدي لمجمو عتين إحداهما تجريبية و الآخري ضابطه نظر ال لناسبته لطبيعة هذا البحث.

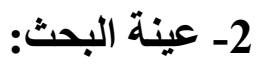

اشتمل مجتمع البحث على ناثئي سباق 100م عدو و المسجلين بالإتحاد الصصري لألعاب القوي موسم

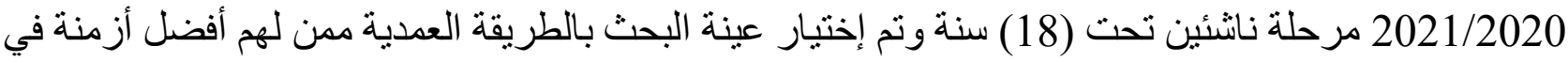

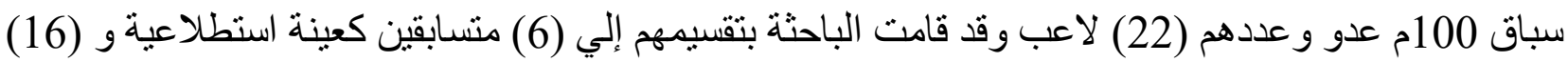
لاعب كعينة اساسية مقسمين إلي (8) متسابقين كعينة تجرييية و (8) متسابقين عينة ضابطة . ولضمان التجانس و التكافؤ بين المجمو عتين ، قامت الباحثة بإجر اء توزيع إعتدال قيم لمجتمع البحث في القياسات

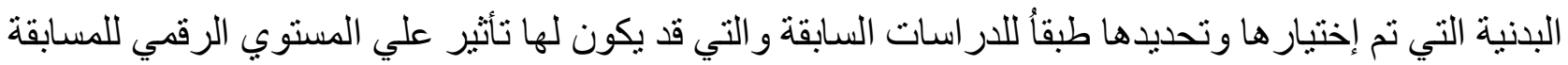
قبد البحث.

\section{جدول (1): تجانس وتكافؤ عينات المجموعتين على متغيرات البحث}

تجانس عينة البحث الكلية لبعض القدرات البذنية الخاصة وقوة عضلات الطرف السفلي والمستوي الرقمي

$$
\text { لناشئ } 100 \text { متر عدو. }
$$

\begin{tabular}{|c|c|c|c|c|c|}
\hline معامل & الوسيط & الانعياري & الحسابي & وحدة & 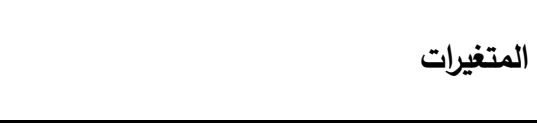 \\
\hline $0.86^{-}$ & 3.99 & 0.14 & 3.95 & ثانية & عدو 30 متر من البدء الطائر \\
\hline $0.15^{-}$ & 14.84 & 0.25 & 14.83 & ثانية & عدو 120 متر من البدء العالي \\
\hline 0.99 & 6.19 & 0.31 & 6.29 & 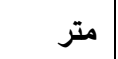 & إختبار ثلاث حجلات لأكبر مسافة القدم اليمني \\
\hline 0.63 & 6.20 & 0.27 & 6.26 & 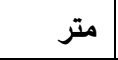 & إختبار ثلاث حجلات لأكبر مسافة القدم اليسري \\
\hline $0.53-$ & 11.50 & 2.05 & 11.14 & 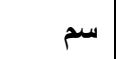 & ثني الجذع أماما أسفل من الجلوس \\
\hline $0.23-$ & 12.84 & 0.25 & 12.82 & ثانية & قياس المستوي الرقمي 100 متر عدو \\
\hline
\end{tabular}


يتضح من الجدول (1) أن قيم معاملات الإلتو اء للققر ات البدنية الخاصة وقوة عضلات الطرف السفلي

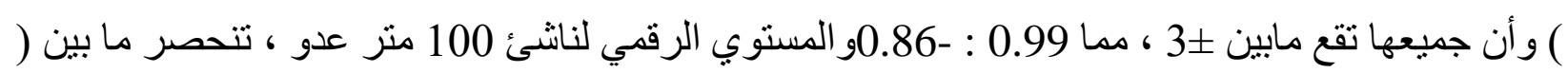

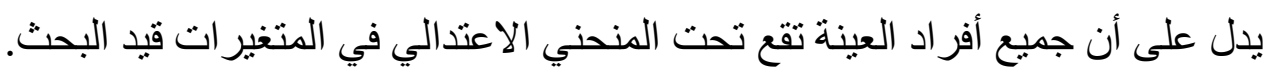

الاختبارات و القياسات المستخدمة في البحث:

-

- ق قياس السرعة الإنتقالية (القصوي): عدو 30 منر من البدء الطائر.

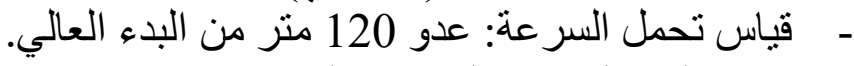

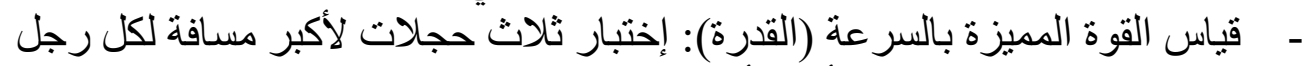

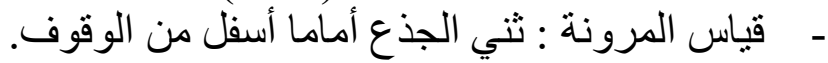

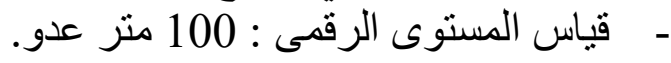

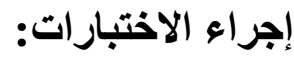

- م تم إجر اء الفحص الطبي علي جميع المتسابقين للتأكد من خلو عينة البحث من أي أمر اض أو إصابات

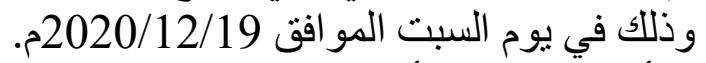
- - تم أخذ القياسات الأنثروبومترية (الطولـالوزن) لعينة البحث وذلك في يوم السبت المو افق 2020/12/19

تم إجراء إختبارات المستوي الرقمي والمراحل الفنية الخاصة المستخدمة قيد البحث لأفراد العينة للقياسات

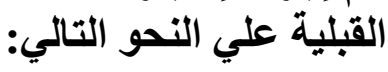

- ق قياس السرعة الإنتقالية (القصوي): عدو 30 متر من البدء الطائر وذلك في يوم الأحد الموافق 2020/12/20 - قياس تحمل السر عة: عدو 120 منر من البدء العالي وذللك في يوم

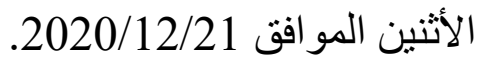
- قياس القوة المميزة بالسر عة (القدرة): إختبار ثلاث حجلات لأكبر مسافة لكل رجل وذلك في يوم

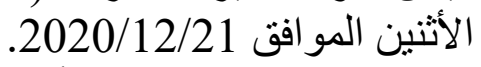
الثناثاء المو افق : 2020/12/22.

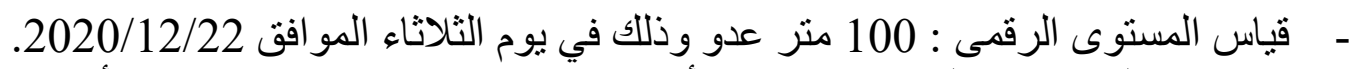

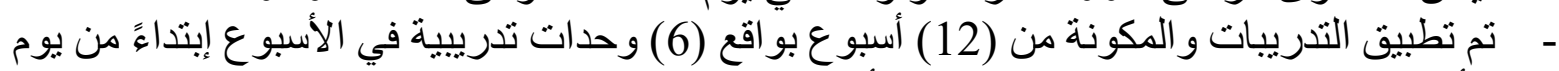

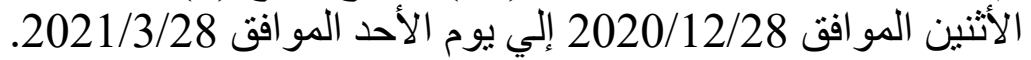




\begin{tabular}{|c|c|c|}
\hline التوزيع الزمني & المحتوي & s \\
\hline 3 شهور & مدة تطبيق التدريبات & 1 \\
\hline 12 أسبوع & عدد الأسابيع & 2 \\
\hline 6 وحدات تدريبية & عدد الوحدات في الأسبوع & 3 \\
\hline 72 وحدة تدريبية & العدد الكلي للوحدات التدريبية & 4 \\
\hline 6520 دقيقة / 109 ساعة & الزمن الكلي للوحدات التدريبية & 5 \\
\hline إلي 2020/12/28 من 2021/3/28 & الفترة & 6 \\
\hline
\end{tabular}

الاختبار ات اللاحقة:

وذلك في الفترة من يوم السبت المو افق 2021/3/29 إلي يوم الأثنين المو افق 2021/3/31 بنفس طريقة القياس القبلي وبنفس الثروط.

أساليب إحصائية:

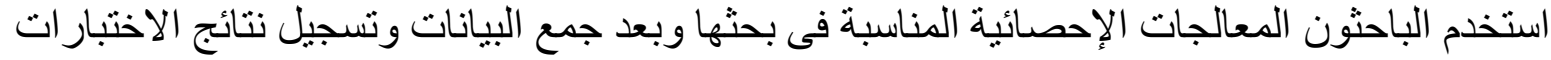

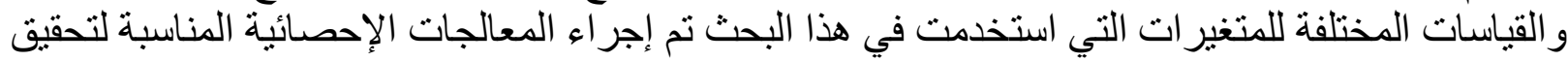

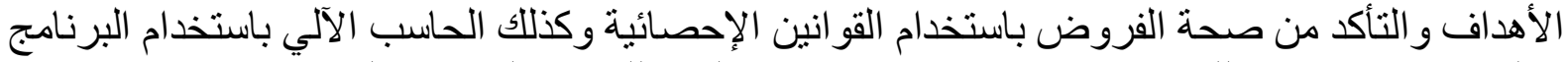

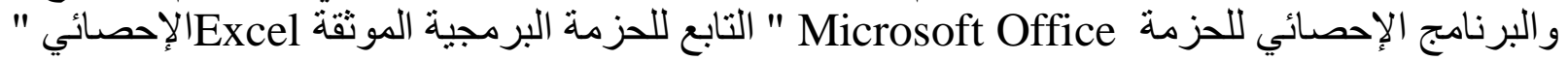

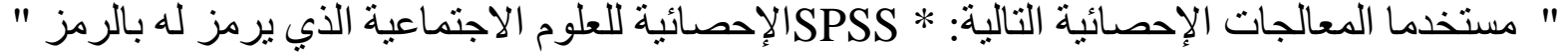

$$
\begin{aligned}
& \text { الوسيط } \\
& \text { إختبار مان ويتني } \\
& \text { الإنحر اف المعيارى } \\
& \text { معامل الإرتباط } \\
& \text { المتوسط الحسابى الإلي أ } \\
& \text { معامل الإلتو اء } \\
& \text { معادلة نسب التحسن الإطب } \\
& \text { إختبار ولكوكسون }
\end{aligned}
$$

وقد تبنى الباحثون مستوى معنوية 0.05 حداً للالالة الإحصائية. 
عرض وتحليل ومناقثة نتائج الاختبارات الأولية واللاحقة للمجموعة الضابطة: جدول (2)

دلالة الفروق بين القياس القبلي والبعدى في بعض القدرات البذنية الخاصة وقوة عضلات الطرف السفلي والمستوي الرقمي لناشئ 100 متر عدو لدي المجموعة الضابطة. ن = 8

\begin{tabular}{|c|c|c|c|c|c|c|c|}
\hline \multirow{2}{*}{$\begin{array}{r}\text { الاحتمال } \\
\text { Sig.(p.val } \\
\text { ue })\end{array}$} & \multirow{2}{*}{ إحصائي } & \multicolumn{2}{|c|}{ متوسط الرتب } & \multirow{2}{*}{ اللقياس } & \multirow{2}{*}{ القلقياس التسابي } & \multirow{2}{*}{ القياس } & \multirow[b]{2}{*}{ المتغيرات } \\
\hline & & $\begin{array}{r}\text { الإشارات } \\
\text { (+) }\end{array}$ & $\begin{aligned} \text { الإثارات } & \text { ( ) }\end{aligned}$ & & & & \\
\hline 0.944 & 0.07 & 4.38 & 4.62 & 3.96 & 3.97 & ثانية & عدو 30 متر من البدء الطائر \\
\hline 0.327 & 0.98 & 5.50 & 4.17 & 14.72 & 14.81 & ثانية & عدو 120 متر من البدء العالي \\
\hline 0.528 & 0.63 & 4.50 & 4.50 & 6.34 & 6.23 & متر & القدام اليمني ثلاث حجلات لأكبر مسافة \\
\hline 0.463 & 0.73 & 3.50 & 3.50 & 6.28 & 6.20 & متر & القدم اليسري ثلاث حجلات لأكبر مسافة \\
\hline 0.799 & 0.25 & 5.17 & 3.12 & 11.13 & 10.75 & سم & ثني الجذع أماما أسفل من الوقوف \\
\hline 0.779 & 0.28 & 4.00 & 5.00 & 12.71 & 12.80 & ثانية & عدياس المستوي الرقمي 100 متر \\
\hline
\end{tabular}

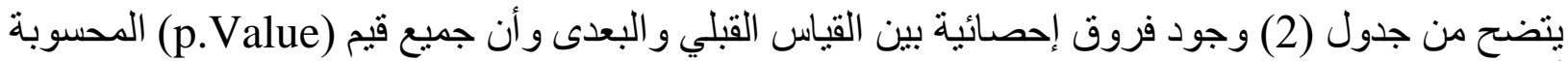

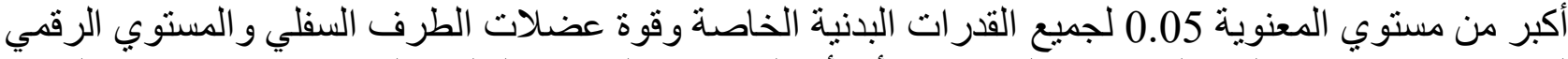

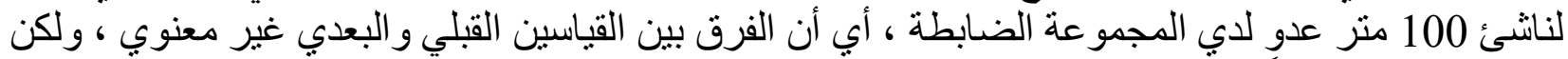
هناك فروق إحصائياً لصالح القياس البعدى .

يتضح من جدول رقم (2) وجود فروق إحصائية بين القياس القبلي و البعدى ولصالح القياس البعدي و أن جميع

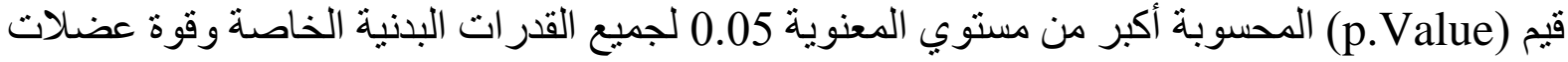

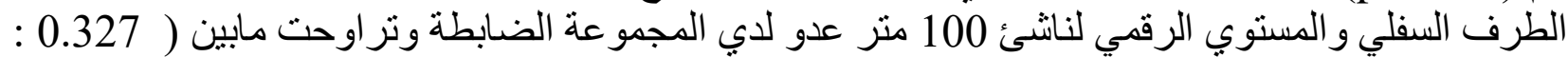

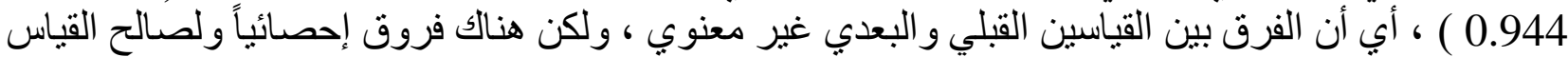
البعدى للمجموعة الضابطة التي تستخدم البرنامج التقليدي . 
ويرجع الباحثون هذا التقام الحادث في مستوى الإنجاز الرقمي للمجموعة الضابطة إلي تأثير البرنامج التندريبي

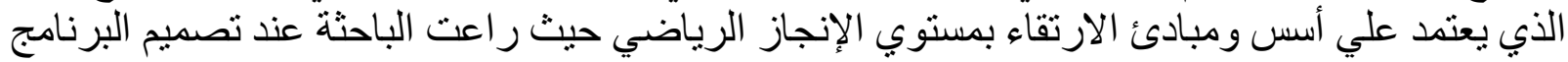

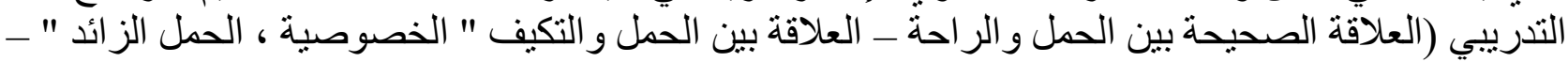

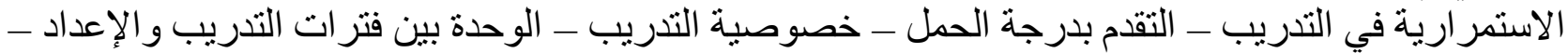

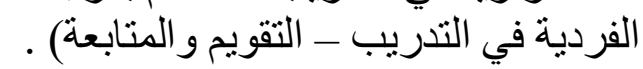

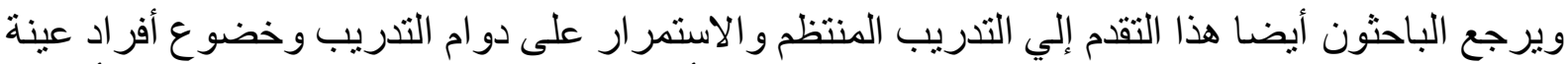

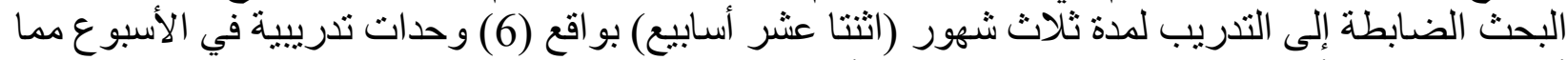
أدى إلى وصول أفر اد العينة إلى مرحلة التكيف للأحمال المرتفعة للتندريبات التقليدية.

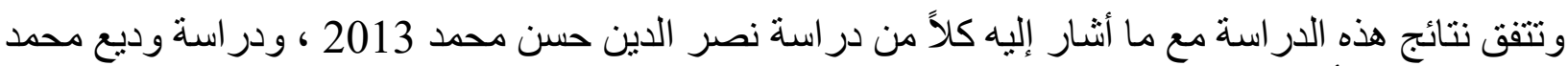

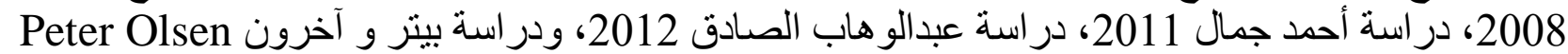
2003 على أهمية الإستمر ار علي أداء التدريبات التخصصية وقدرتها علي رفع مستوي اللاعب .

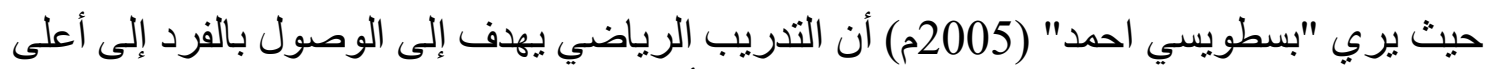

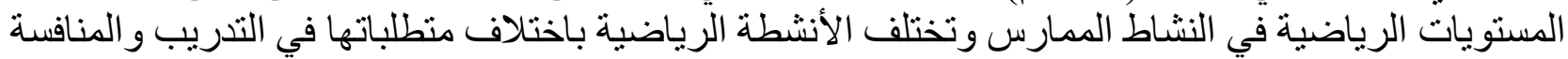

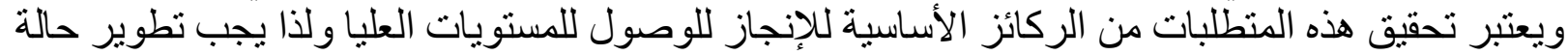
الفرد بما يتلاءم مع كل هذه المتطلبات. (10: 69 )

حيث يشير "إياد عبدالله" (2012م) على ان علم التدريب الرياضي يتناول العديد من الوسائل التدريبية

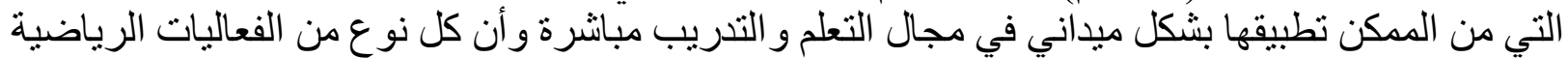

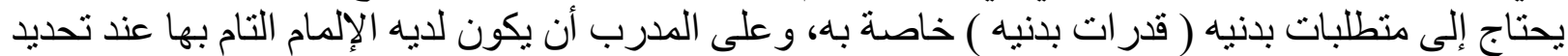

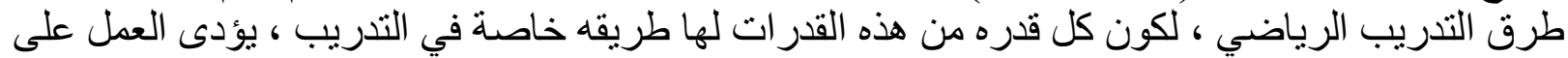

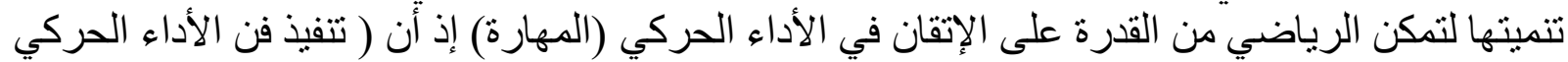
بشكل منقن يكون دليل البناء البدني. (6: 11 11)

بناءاً علي ما سبق نتائج تم عرضها في الجداول و الاثكال السابقة و التعليق عليها ومناقتشتها وتفسيرها،

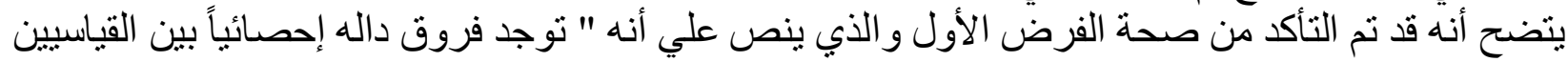

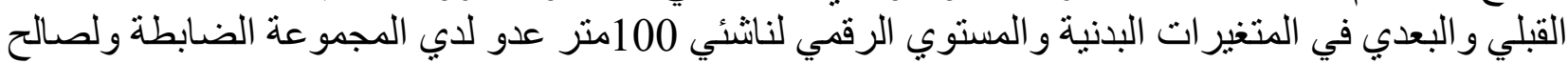




\section{عرض وتحليل ومناقشة نتائج الاختبار ات الأولية والبعدية للمجموعة التجريبية:}

\section{جدول (3)}

دلالة الفروق بين القياس القبلي والبعدى في بعض القدرات البذنية الخاصة وقوة عضلات الطرف السفلي والمستوي الرقمي لناشئ 100 متر عدو لاي المجموعة التجريبية

$8=ن$

\begin{tabular}{|c|c|c|c|c|c|c|c|}
\hline \multirow{2}{*}{ Sig.(p.value } & \multirow{2}{*}{$\begin{array}{r}\text { إحصائي } \\
\text { والاختبار } \\
\text { ولكوكسون } \\
\end{array}$} & \multicolumn{2}{|c|}{ متوسط الرتب } & \multirow{2}{*}{ اللقياس البوسي } & \multirow{2}{*}{ |الحسابي } & \multirow{2}{*}{ | القياس } & \multirow[b]{2}{*}{ المتغيرات } \\
\hline & & $\begin{array}{r}\text { الإشارات } \\
(+)\end{array}$ & $\begin{array}{r}\text { الإثارات } \\
\text { ( ) }\end{array}$ & & & & \\
\hline 0.012 & 2.52 & 0.00 & 4.50 & 3.76 & 3.87 & ثانية & عدو 30 متر من البدء الطائر \\
\hline 0.012 & 2.52 & 0.00 & 4.50 & 13.93 & 14.76 & ثانية & عدو 120 متر من البدء العالي \\
\hline 0.012 & 2.53 & 4.50 & 0.00 & 6.71 & 6.49 & 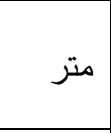 & إلقدبار ثلاث حجلات لأكبر مسافة \\
\hline 0.011 & 2.53 & 4.50 & 0.00 & 6.61 & 6.43 & متر & إلقدبار ثلاث حجلات لأكبر مسافة \\
\hline 0.010 & 2.59 & 4.50 & 0.00 & 13.63 & 10.88 & | - اسم & ثني الجذع أماما أسفل من الوقوف \\
\hline 0.012 & 2.52 & 0.00 & 4.50 & 12.23 & 12.76 & ثانية & قدياس المستوي الرقمي 100 متر \\
\hline
\end{tabular}

$0.05>\operatorname{Sig}($ p.value) دال إحصائيا عند *

يتضح من جدول (3) وجود فروق معنوية إحصائية بين القياس القبلي و البعدى و أن جميع قيم (p.Value)

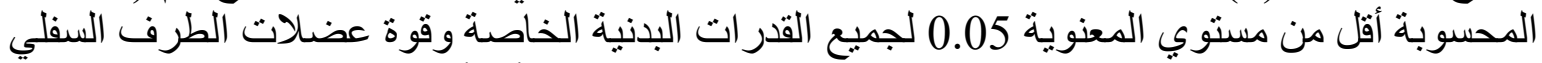

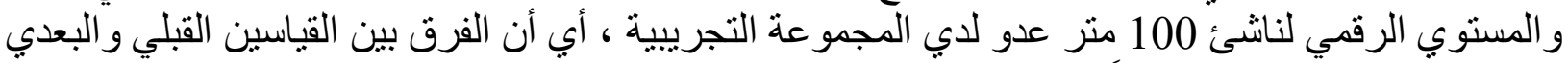

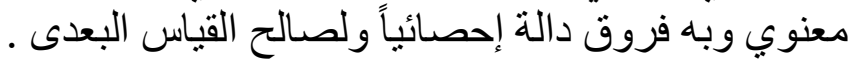

يتضح من جدول رقم (3) وجود فروق دالة إحصائية بين القياس القبلي و البعدى ولصالح القياس البعدي وأن

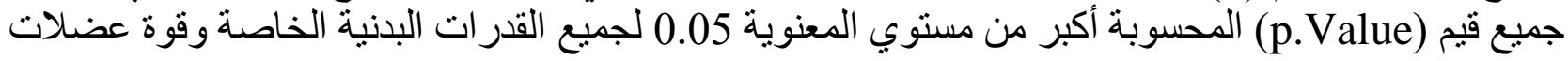

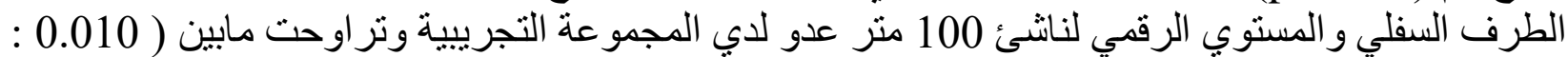

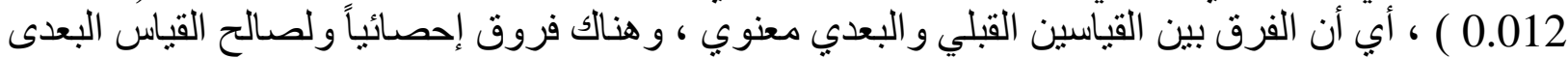

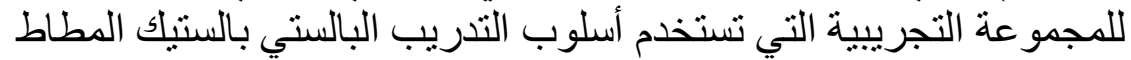


ويرجع الباحثون هذا التقام الحادث في مستوي الإنجاز الرقمي للمجموعة التجريبية إلي تأثير البرنامج التنديبي

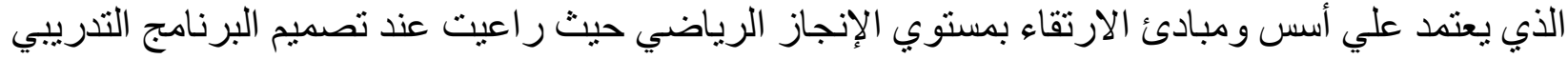

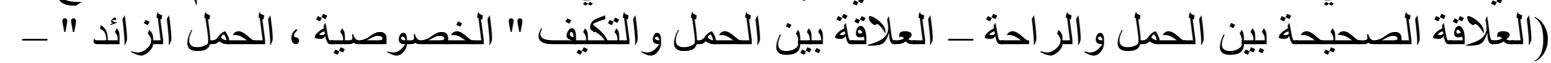

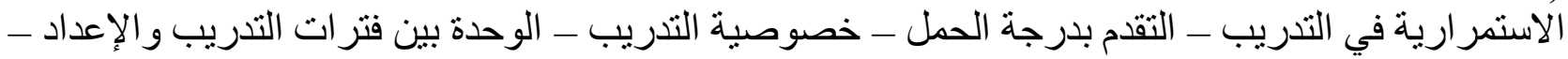

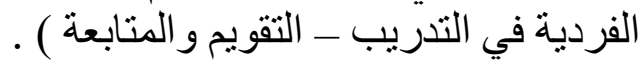

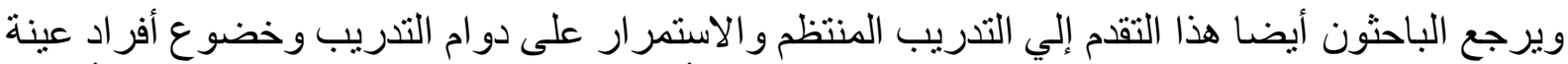

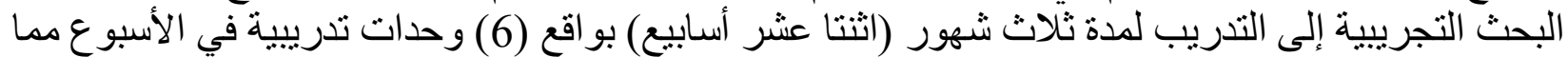
أدى إلى وصول أفر اد العينة إلى مرحلة التكيف للأحمال المرتفعة لتنديبات الأستأك المطاط و التندريبات التقليدية.

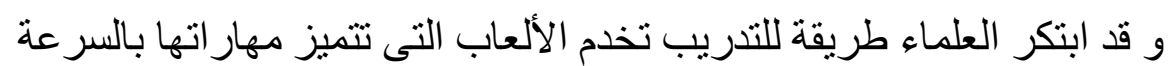

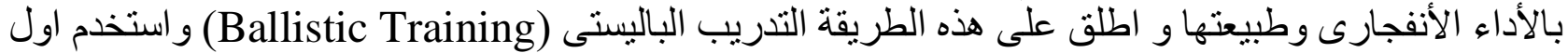

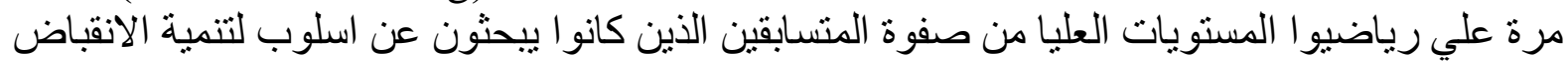
العضلي التلقائي الانفجاري العنيف.

وللتعرف على الفرق بين المجمو عتين الضابطة والتجريية في اختبار ات الأبعاد لمتغير ات البحث نجد الآتي:

جدول (4)

نسبة التحسن المئوية في بعض القدرات البلنية الخاصة وقوة عضلات الطرف السفلي والمستوي الرقمي لناشئ

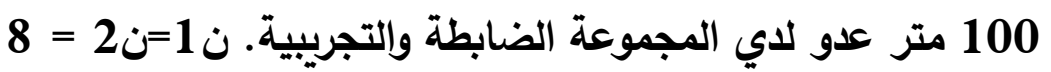

\begin{tabular}{r|r|r|r|r|r|r}
\hline \hline \\
\hline
\end{tabular}


يتضح من الجدول رقم (4) وجود نسب تحسن مئوية بين القياسين القبلى والبعدى ولصالح القياس البعدي

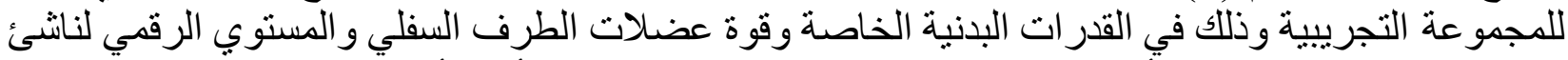

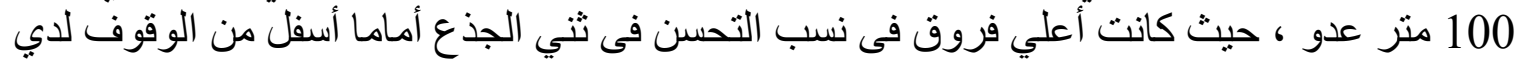

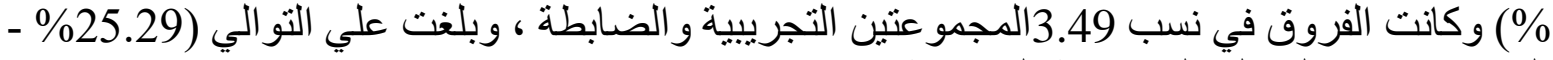
التحسن جميعها لصالح المجمو في فئ التجريبية .

(5) جدول

دلالة الفروق بين المجموعتين الضابطة والتجربيية لاي القياس البعدي في بعض القدرات البدنية الخاصة وقوة

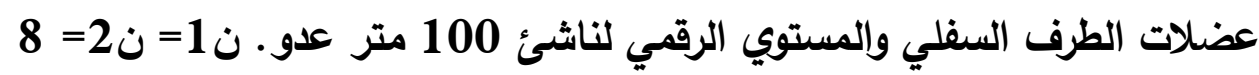

\begin{tabular}{|c|c|c|c|c|c|c|c|}
\hline \multirow{2}{*}{$\begin{array}{r}\text { الاحتمال } \\
\text { Sig.(p.value) }\end{array}$} & \multirow{2}{*}{ 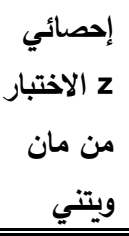 } & \multicolumn{2}{|c|}{ متوسط الرتب } & \multirow{2}{*}{ اللمجسابي } & \multirow{2}{*}{ اللمجموعة المتبط } & \multirow{2}{*}{ القياس } & \multirow[b]{2}{*}{ المتفيرات } \\
\hline & & التجريبية & الضجمةعة المجابطة & & & & \\
\hline 0.058 & 1.89 & 6.25 & 10.75 & 3.76 & 3.96 & 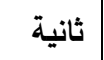 & عدو 30 متر من البدء الطائر \\
\hline 0.001 & 3.36 & 4.50 & 12.50 & 13.93 & 14.72 & 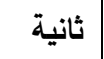 & عدو 120 متر من البدء العالي \\
\hline 0.021 & 2.31 & 11.25 & 5.75 & 6.71 & 6.34 & 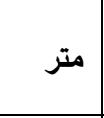 & إختبار ثلاث حجلات لأكبر مسافة القدم \\
\hline 0.021 & 2.31 & 11.25 & 5.75 & 6.61 & 6.28 & متر & إختبار ثلاث حجلات لأكبر مسافة القدم \\
\hline 0.423 & 0.80 & 9.44 & 7.56 & 13.63 & 11.13 & 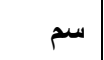 & ثني الجذع أماما أسفل من الوقوف \\
\hline 0.002 & 3.05 & 4.88 & 12.12 & 12.23 & 12.71 & 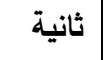 & قياس المستوي الرقمي 100 متر عدو \\
\hline
\end{tabular}

$0.05>$ Sig (p.value) دال إحصائيا عند *

يتضح من جدول رقم (5) وجود فروق دالة إحصائية بين المجمو عتين التجريبية و الضابطة فى القياس البعدي في القدرات البدنية الخاصة وقوة عضلات الطرف السفلي و المستوي الرقمي لناشئ 100 متر عدو وجميعها لصنالح المجمو عة التجريبية. 
- حققت المجموعة الضابطة تحسنا في المتغير ات البدنية والمستوي الرقمي

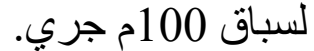
- حققت المجموعة ألتجريبية تحسنا في المتغير ات البدنية و المستوي الرقمي

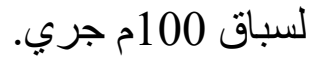

- إن استخدام التنديبات الباليستية بالأستيك المطاط لها أثر و اضح علي تطوير المتغيرات البدنية الخاصة و المستوى الرقمى التي انعكست بشكل و اضح علي تحسن المستوي الرقمي لسباق النس 100م جري.

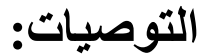

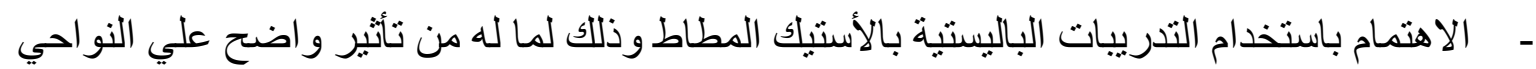

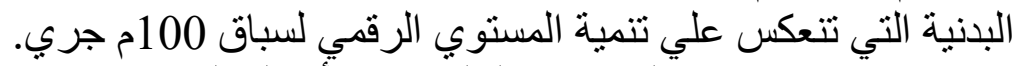

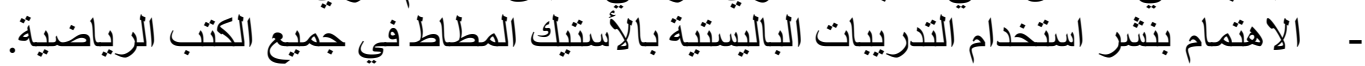

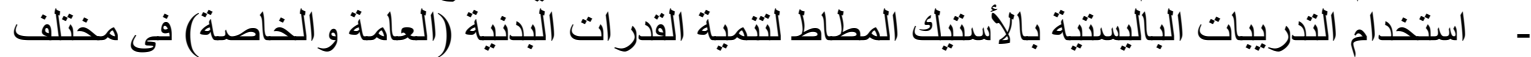

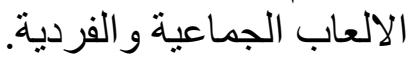




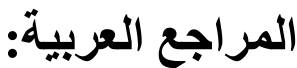

1 2 البوالعلا عبد الفتاح واحمد نصر الدين1993: فسيولوجيا اللياقة البدنية , الطبعة الاولي دار الفكر العريي 3

احمد خليفة حسن :تأثير استحدام التدريب الباليستي المركب المشترك علي بعض المتغيرات البدنية والمهارية 4

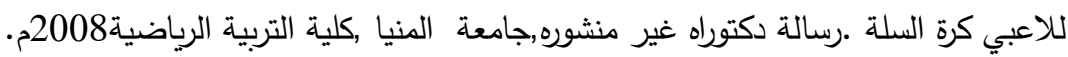
اسلام خليل عبد القادر تأثير إستخدام التدريب المائي علي تنمية القدره العضلية للاعب الكره الطائره رساله ماجيستير كليه تربيه رياضيه للبنين جامعه بنها ج . . r. اياد محمد عبدالله : 2012 نسبة مساهمة اهم الصفات البدنية وعلاقتها بالمستوي الرقمي في الوثب العالي والمستوي الرقمي لسباق 800 متر جري لتلاميذ المدارس الثانوية الرياضية التجريبية ، رسالة دكتوراه غير منشورة ، كلية التربية الرياضية ببورسعيد ، جامعة قناة السويس.

ايهاب احمد راضي :دراسة مقارنة بين التدريب البالستي والتدريب بالاتقال علي بعض القدرات البدنية

والمستوى الرقمي لمتسابقي الوثب الطويل ,رسالة ماجيستير غير منشورة ركلية التربية الرياضية ,جامعة المنيا 2007,

إبراهيم سالم السكار وآخرون : موسوعة فسيولوجيا مسابقات المضمار ، ط1 ، مركز الكتاب للنشر ، القاهرة ،

بسطويسي احمد بسطويسي : سباقات المضمار , ومسابقات الميدان ,تعليم , تكنيك , تدريب , دار الفكر

بسطويسي احمد" (2005م): المدخل لمعني مفهوم اهمية العمل البليوميتري, الاتحاد الدولي لالعاب القوي للهواه, مركز التتمية الاقليمي , الحلقة الاولي ,نشرة العاب القوي , العدد 81 , القاهرة. 
حسن عبد الله احمد عبد ربه:تأثير برنامج تدريبات الوسط المائي علي بعض المتغيرات البيلوجية والمستوي الرقمي لمتسابقي عدو المسافات القصيرة بالجمهورية اليمنية , رسالة دكتوراه غير منشورة , كليه التربيه الرياضيه للبنين , جامعه حلوان , القاهرة 2006م.

$$
\text { خيريه السكرى وسليمان حسن" (2007م) :مسابقات الرمي, دار المعارف , القاهرة. }
$$

رشا مصطفي مبروك ,داليا محمد سيد هاشم: دراسة مقارنة لتأثير اسلوبي المقاومه القذفية ودورة الاطالة والتقصير علي بعض المتغيرات البدنية والمهارية للاعبي كرة الطائرة ,المجلة العلمية للتربية البدنية والرياضية

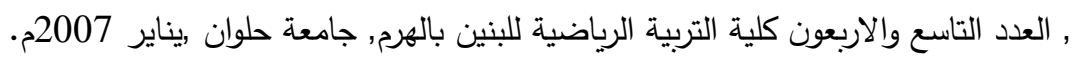
ريسان خريط مجيد , عبدالرحمن الانصاري : العاب القوي -الدولية للنشر والتوزيع -عمان 2002م.

شريف علي محمد جلال : تأثير برنامج تدريبي بالمقاومات علي بعض المكونات البدنية ومستوي الانجاز الرقمي للسباحي الحره , رسالة ماجيستير غير منشورة , جامعة الزقازيق , 2008م.

صفاء صلاح الدين حسين 2008م :تأثير التدريبات التبادلية الباليستية والقانون دافا علي بعض المتغيرات الوظيفية , والعقلية لاي لاعبات الكارتية ,بحث منشور , المجلة العلمية,

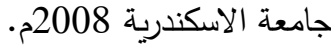

طلحة حسام واخرون"(2005م):الموسوعة العلمية في التدربب الرياضي ,مركز الكتاب للنشر ,القاهرة ط 2.

طلحه حسام الدين , وفاء صلاح الدين ,مصطفي كامل احمد , سعيد عبد الرشيد : الموسوعة العلمية في

$$
\text { التدريب الرياضي , مركز الكتاب للنشر , القاهره , 1997م. }
$$


عادل حلمي: دراسة أثر تدريبات التحكم في التنفس علي بعض المتغيرات الفسيولوجية ومستوي الإنجاز الرقمي لمتسابقي 800 م جري ("رسالة ماجستير غير منشورة كلية التربية الرياضية للبنين

عبد الرحمن عبد الحميد زاهر :ميكانيكية تدريب وتدريس مسابقات العاب القوي , ط (1) , مركز الكتاب

عبد العزيز احمد النمر : تأثير تدريبات الوثب العميق علي زيادة مسافة الوثب العمودى للاعبي كرة السلة ,

رساله ماجيستير غير منشورة , كلية تربية رياضية , جامعة حلوان 1989.

عبدالباسط محمد عبدالحليم، أشرف عبدالعزيز أحمد: "دراسة مقارنة بتأثير التدريب علي الرمال والتدريب في

الماء علي بعض المتغيرات الفسيولوجية ومكونات اللياقة البدنية الخاصة للاعبي كرة القدم" بحث علمي منشور ، المجلة العلمية للعلوم والتربية البدنية والرياضية، جامعة المنصورة، العدد السادس مارس 2006. عصام عبد الخالق: التدريب الرياضى "نظريات - تطبيقات" ، ط10 ، دار الفكر العربى ، القاهرة ، 2000م.

علي فهمي البيك و عماد الدين عباس : سلسلة الاتجاهات الحديثه في التدريب الرياضي "نظريات -تطبيقات الجزء الثالث(طرق واساليب التدريب لتمية وتطوير القدرات اللاهوائيه والهوائيه ) منشأه المعارف , الاسكندريه .2008,

علي محمد طلعت :تأثير استخدام تدريب المقاومة الباليستية علي بعض المتغيرات البدنية والمهاريه للاعبي كرة السلة , رسالة ماجيستير غير منشورة , كلية التربية الرياضية بنين , جامعة حلوان 2003م.

عويس الجبالي" (1998م) سلسلة المناهج المنطية منهاج العاب القوى_المجلس الاعلي للشباب والرياضة , 1998م.

محمد جابر بريقع و ايهاب فوزي البديوي:التدريب العرضي "اسس-مفاهيم-تطبيقات "منشأه المعارف , الاسكندريه 2004م. محمد حسن علاوى : علم التدريب الرياضى ، دار المعارف ، ط13 ، القاهرة ، 1992م. 
محمد محمود لبيب : دراسة مقارنة لتأثير استخدام اسلوبين مختلفين لتتمية القدرة العضلية (البليوميتري الكارتية , رساله ماجيستير غير منشورة , كليه تربية رياضية , جامعه حلوان , 2000م.

مصطفي احمد السيد محد :تأثير كلا من التدريب الباليستي والبليومتري علي القدرة العضلية وتحسين الاداء للاعبي الكومتية ,رسالة ماجيستير غير منشورة , كلية التربية الرياضية للبنين ,

مي عصام محمد حمودة : تأثير استخدام التدريبات الباليستية علي تتمية القدرة العضلية والمستوي الرقمي

لدفع الجلة , بحث منشور المؤتمر العلمي الدولي الثالث ,كلية التربيه الرياضية للبنين , جامعة الزقازيق مارس

نجلة عبد المنعم بحيري :برنامج مقترح بأستخدام التدريبات الباليستية على تتمية القدرة العضلية والمستوى الرقمي لافع الجلة ربحث منشور ,المجلة العلمية للتربية البننية والرياضية ,كلية التربية الرياضية للبنين,جامعة بلية

$$
\text { الزقازيق ,2009م. }
$$

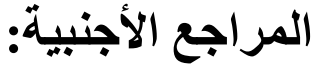

41 CHARLES STALEY :FUNDAMENTALS OF STRENGTH ACQUISTITION FOR COMBAT SPORTS STALEY@WESTNET,INTERNATI ONAL SPORTS SCIENCES ASSOCIATION (1996) 
42 FLECK S.AND KRAMER W.J :DESIGNING RESISTANCE TRAINING PROGRAM .3RD ED.HUMAN KINETICS CHAMPAIGN ,NEWYORK U.S.A ,2004.,

43 GEORGE BLOUGH DINTIMAN, ROBERT D WORD : THE LATHELETE TRAINING PROGRAM SPORTS SPEED THIRD EDITION,2003

44 Gigi M. Berardi (2005):Finding Balance: Fitness, Training, and Health for a Lifetime in Dance, Published by Routledge, ISBN 0415943388 , 9780415943383275 pages

45 KERRY P.MC-EVAOY AND ROBERT U .NEWTON : BASE BALL THROWING SPEED AND BSE RAMMING SPEED ,THE EFFECTS OF BALLISTIC RESISTANCE TRAINING ,JOURNAL OF STRENGTH AND CONDITION RESEARCH ,VOLUME 12 NUMBER4,NOVEMBER,1998

46 Lee E. Brown(2007):Strength Training, Published by Human Kinetics, U.S.A

47 Marc Evans(1997):Endurance athlete's edge, Human Kinetics,USA

48 Phillip Page, Todd S. Ellenbecker(2003):The Scientific and Clinical Application of Elastic Resistance, Published by Human Kinetics,U.S.A 
49 Phillip Page, Todd S. Ellenbecker(2005) :Strength Band Training: over 100 exercises for using resistive bands and tubing, Published by Human Kinetics,U.

50 ZEHER EP ,SALE D : BALLISTIC MOVEMENT MUSCLE ACTIVATION AND NEW MUSCLAR ADAPTATION CONDITION,JOURNAL OF APPLIED PHYSIOLOGY ,DECEMBER,1994.

51 WWW.CORMAXFITNESS.COM 2013:2014 